Consider alone the outlay necessary to bring housing conditions up to a healthful point in our cities. More than almost any other disease tuberculosis possesses social phases, and the physician who comes into even occasional contact with it may well pause to consider whether in his handling of a case the obligations to society are properly considered. We have the opportunities and abilities to see clearly the basic causes of this far-reaching scourge. Our position has enabled us to trace out the human faults and deficiencies that produce the thing. No other profession, no other group of people, knows so well when humanity begins, by its omissions and commissions, to endanger itself with this trouble. Ours being the first eyes to see the impending misfortune, so also is ours the duty to warn early against the dangers, - to counsel in private and public the truths we know, to teach, to preach, to educate,- to create, in short, public enlightenmont.

Let the profession realize that the pioneer tuberculosis physicians have known well what they needed in state institutions to make success, but that they must wait for the consent of legislative bodies. Let us realize that slow progress can often be traced to bad polities and we will see clearly what the remedy is.

Help to disseminate the information that able physicians often shun public institutions because of the dangers and futile obstacles therein.

Able hospital superintendents deserve cooperation and support from the profession. The percentage of recoveries being dependent greatly upon a complete authority and control of patients, it follows that coöperation by the profession with the hospital staff will assist to increase recoveries by establishing confidence and cooperation between patients and staff. We should attempt to aid the staff to have untrammeled authority and power.

Let us have a policy in regard to our city and county tuberculosis hospitals. These are chiefly isolation places, and the management will require chiefly palliative measures until the end. But some curable cases may enter here, and for them an aggressive, particular routine must be instituted or they may fail to recover.

\section{MORTALITY AFTER PROSTATECTOMY, BASED ON A STUDY OF 229 FATAL RESULTS.*}

\section{By Benjamin Tenney, M.D., Boston, AND \\ Henry M. Chase, M.D., Boston.}

The observations which this paper presents are obtained from the consideration of 106 fatal cases following prostatectomy contributed for our

* Rend at the anuunal meeting of the American Lirological Asso. - ciution in Philueleluhin. 1014. study by members of the Ameriean Lrological Society, from other cases already in print and from a paper on Mortality after Prostatectomy published by us in 1906.

As many of the reports cover cases dying before our modern methods of investigation became common and others have been made up from incomplete records, the totals of the different observations vary. It may be regretted that this paper does not cover the percentage of recoveries as well. Possibly this may be taken up at another time, but this paper will be confined to a study of fatal cases and their relation to the conditions which existed before operation.

We have discarded the reports on eases operated under fifty years of age as likely to be complicated by acute infection of the urinary tract and by eancer. One hundred and sixty cases arranged by decades with the eause of death appear in Table I.

\begin{tabular}{|c|c|c|c|c|c|c|c|c|c|}
\hline & $80-80$ & $0-60$ & $70-78$ & $0-80$ & $\infty$ & otals: & $\begin{array}{c}\text { Oapose } \\
\text { Fro. } \\
\text { Proverout } \\
\text { Paper }\end{array}$ & & teds \\
\hline Dremie & 7 & 18 & 10 & 3 & & 41 & 28 & $\infty$ & $30 \%$ \\
\hline sepas. & 1 & - & 8 & 1 & & 10 & - & 25 & $11 x$ \\
\hline Beaporrhage & 3 & 10 & 23 & 4 & & 30 & 11 & 80 & $22 x$ \\
\hline sbook & 1 & 3 & 8 & & & 0 & & & \\
\hline mbol1en & 3 & 12 & 7 & 2 & & 24 & 3 & 87 & $18 x$ \\
\hline Pulmonary & 1 & 3 & 8 & 4 & 1 & 14 & 8 & 22 & 108 \\
\hline oardece & 1 & 4 & $\bullet$ & 2 & & 12 & 2 & 21 & $\alpha x$ \\
\hline $\begin{array}{l}\text { Goneral } \\
\text { Dentilits }\end{array}$ & & 3 & 2 & 1 & & - & 1 & 7 & $3 \pi$ \\
\hline Lo1dooses & & 1 & 1 & & & 2 & 0 & 2 & 18 \\
\hline Loo1dont & 1 & 2 & & & & s & $\bullet$ & $\bullet$ & 4 \\
\hline & & & & & & & & & \\
\hline
\end{tabular}

It appears that there were more deaths from uremia than from any other one cause. We have listed the deaths from sepsis next because some deaths assigned to this cause occurred so early as to suggest the influence of renal inadequacy in producing so early fatal results. Legueu goes even further and in a recent paper says: "Minute investigation of the conditions under which prostatic patients die compels us to attach more and more importance to renal insufficiency. Death from uremia fully explains the accidents currently ascribed to embolism or pulmonary complications which in reality only play a secondary part. It would seem that alongside and vastly more than the liver, lung and heart it is the kidneys which most frequently kill our patients after operation and which furnish the underlying cause of many of the pathological troubles in those who recover."

The next most frequent cause of death is hemorrhage and we have listed shock after this because the two are so often associated and because some patients who were said to have died of shock lived for twenty-four hours or more before the end came.

It is our opinion that a reduction in mortality from these two causes is possible and that a dis- 
tinct improvement oyer the results of ten years ago is already here.

The large number of deaths between sixty and eighty corresponds with the larger number of patients who were operated in these decades. Our previous paper, based on 816 operations by many different surgeons, showed that $80 \%$ of all prostatectomies were done on patients in these two decades. It may be interesting to reproduce the table from that paper showing the mortality in the different decades.

- TABLE II =

\begin{tabular}{c|c|c|c|c|c}
\hline Number of Pationte & 120 & 422 & 240 & 24 & 2 \\
\hline $\begin{array}{c}\text { Poroentege of } \\
\text { ratal Oporations }\end{array}$ & 5.84 & 0.54 & 154 & 334 & $00 \%$ \\
\hline
\end{tabular}

This table was made up from ninety-one fatal results in the work of many different operators with a general mortality of ten per cent.

\section{DURATION OF OBSTRUCTION.}

There are 100 cases in which the duration of obstruction can be compared with the cause of death.

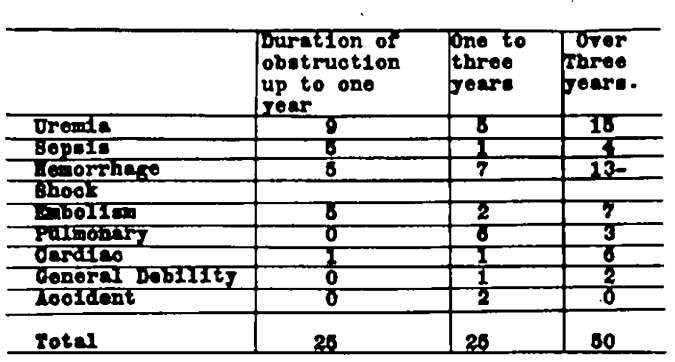

The larger proportion of deaths from uremia sepsis and embolism in patients operated within a year of obstruction, suggests that patients with impaired renal and circulatory apparatus are more likely to seek help early than those who have no disabilities outside of the bladder.

\section{PREPARATION UNDER IIOSPITAL CONDITIONS.}

There are 101 cases in which the preparation under hospital conditions can be compared with the cause of death.

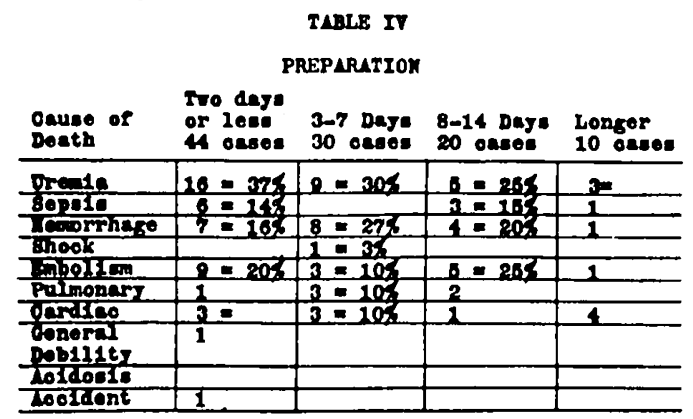

The diminishing percentage of deaths from uremia, as we compare the immediate operations with those delayed is ecrtainly suggestive of the desirability of preparation before operation.

Along this same line it appears in Dr. Hugh H. Young's monograph of 1906 that while some few of his patients were operated within a day or two of admission, there was an average delay of more than eighteen days. You will remember that he reported seven deaths in a total of one hundred and forty-five cases.

\section{PRELIMINARY DRAINAGE.}

Thirty-six of these fatal cases were drained by eatheter and ten by cystotomy before the prostatectomy. Drainage varied from one to ninety days. Fifteen were drained less than one week.

\section{- tabir $\nabla$ -}

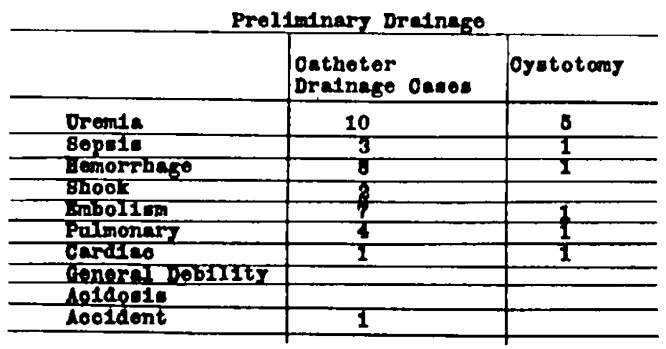

These cases show nothing except that the drainage used was not adequate to protect them from the usual proportion of deaths from uremia, hemorrhage and embolism. It is a question whether drainage for less than a week makes any material difference in the condition of the bladder and kidneys.

If we are to drain before operation we should do it for a certain effect rather than for a certain number of days. If there is any reason for using drainage in preparation of patients that reason should be removed before drainage is given up. The replies to our question are too few to show anything as to the comparative value of long and short preliminary drainage.

FUNCTIONAL TESTS.

The results of functional tests are reported in twenty-six fatalities.

- raser VI.

\begin{tabular}{|c|c|c|}
\hline & $\begin{array}{l}\text { Oases with } \\
\text { reot1 onal reste }\end{array}$ & $\begin{array}{c}\text { Gonoral } \\
\text { Poroentafse }\end{array}$ \\
\hline Vremt: & $10 \%$ & $30 \%$ \\
\hline $\begin{array}{l}\text { Shook and } \\
\text { leacorrhage }\end{array}$ & $10 \%$ & $22 x$ \\
\hline Enolla & $23 \%$ & $12 \%$ \\
\hline sops1. & $4 \%$ & $11 \%$ \\
\hline
\end{tabular}

The functional tests reported are phenolsulphonephthalein and urea percentage, the latter in two cases only.

We regret that the number of fatal cases in which some adequate test of renal function was 
made is so small as to be no test of the value of any of these recent methods. It does appear, however, that the percentage of deaths from uremia and sepsis is smaller among cases tested than among the general run of cases. We believe that the rapidity with which the phenolsulphonephthalein appears in the urine is of great value in estimating the progress made by a patient during his days of preparation. The new ferment which makes the estimation of urea in the blood and urine comparatively easy will doubtless bring the "uremic eonstant" into frequent use on this side of the ocean. No report of its use has come among these cases.

The hemoglobin test is reported in eighteen cases only. Four having hemoglobin of $80 \%$ or better died of hemorrhage; six with hemoglobin, between $70 \%$ and $80 \%$, of uremia; four with heinoglobin of $80 \%$ or better died of embolism.

The blood pressure is given in thirty-one cases. Of those with pressure of 200 or over two died of uremia, one of hemorrhage and one of sepsis. Of those with pressure of 140 or below three died of hemorrhage, one of embolism and one of cardiac disease.

The presence of edema is mentioned in only four cases.

In nearly all the cases dying of hemorrhage the mental condition is given as "Good" or "Fair." In the cases dying of uremia the mental condition is given as "Good" or "Impaired."

The effect of "clean bladder" in twenty-six cases is not apparent, one case dying of sepsis which is not far from the general proportion.

\section{ANESTHESIA.}

The anesthesia is reported in 106 cases.

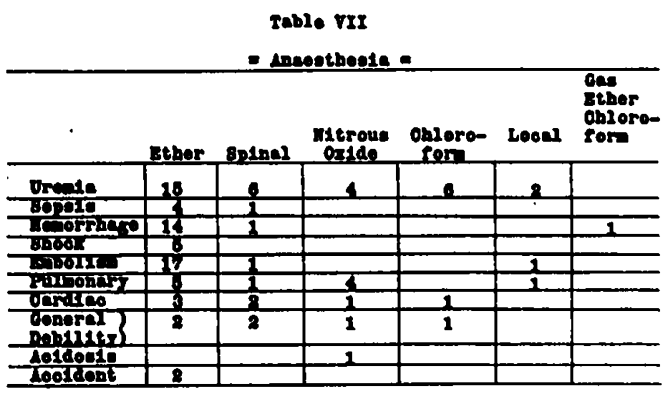

The proportion of deaths from uremia under chloroform and spinal anesthesia is larger than with the other anesthetics which may or may not be due to using these in the worst cases. Certainly neither anesthetic gives perfect security against death from this cause.

The causes of death as related to the type of operation appear in the following table.

Eleven fatalities following the two stage suprapubic operation, and seventeen following the transcapsular perineal operation are included in the above tables as both show the usual causes of death and do not materially alter the above figures. If we may regard the deaths from
TARS VIII

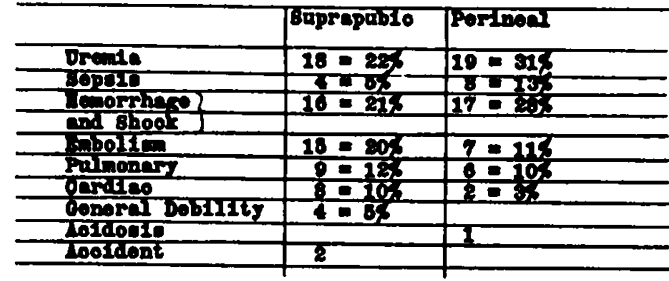

uremia, sepsis, shock and hemorrhage as being more likely preventable than those from other causes, it is worth noting that $48 \%$ of the deaths following the suprapubic route were from these causes, which may be compared with $72 \%$ in the perineal fatalities.

\section{GENERAI, CONSIDERATIONS.}

The three cases dying of accident were one from embolism following air distention of the bladder, one of sudden death with ether anesthesia while the patient was in the Trendelenburg position, and one from distention of the abdominal cavity by irrigating fluid used after the operation.

Under the heading of general debility we have included one case said to have died from acute dilation of stomach.

\section{COMMENTS.}

"I am satisfied that air absorbed through the bladder walls or through a prostatic lesion was the cause of this man's death. I will never use air distention again."

"It is my opinion that the pressure of the perineal drainage tube on the purulent open vein field of the prostatic urethra forced the pus with blood clot into the veins on getting the patient out of bed, and this was followed by an embolic pneumonia and death."

"This patient was operated in a town nearby. I left the day after operation. I have since made it a rule never to operate away from home save in emergency."

"In talking with the various men doing this kind of work, I find that some insist that they will never operate outside of the hospital. I have seen cases in farm houses where something had to be done for relief immediately and where the suggestion of removal would not be listened to. I question very much whether some one will not have to do certain cases outside the hospitals."

"It is to be noted that I have never lost a private patient. All my deaths have occurred in hospital cases in which I was unable to secure the sort of pre-and-post operative treatment upon which I cannot but think so much depends in the question of death or recovery."

\section{SUMMARY}

The greatest danger in the operation of prostatectomy is death from uremia or from condi- 
tions elosely associated with it. After examining a patient we should be able to say that he is a good, fair, or poor risk with reference to this condition. If he is not put in the first class, we should try to put him there before operation or at least get him as near there as possible. Three fatalities from uremia reported to us in patients who had been carefully treated for more than two months, show that we cannot always succeed, but the percentage of deaths from uremia among the cases operated within two days was $37 \%$, while the percentage of deaths from the same cause among patients who were observed long enough to have functional tests made was $19 \%$.

The second great danger in this operation is death from hemorrhage and shock. Is it possible that in our desire to avoid shock by doing a rapid operation, we have sometimes produced shock and hemorrhage by doing a needlessly rough operation? There are reasons in the reports sent us for thinking that this may have had some influence. It is fair to say that a patient whose hemorrhage has been thoroughly controlled seldom starts bleeding again unless the gauze or other means of control is removed too soon. Possibly some operators have been disappointed at nature's failure to stop a leaking vessel which they had failed to close before the patient left the table.

The third serious fatality is embolism, which may also be the cause for some pulmonary complications.

How can we avoid at least a portion of this risk?

Blood vessels are necessarily torn and left untied. The wound is in an infected region and constantly bathed in a septic fluid. A larger raw area is left exposed to this contamination than in almost any other operation. Constant irrigation does not prevent embolism. It occurs when perineal, urethral and suprapubic drainage tubes are used and after both operations. Is it possible that our well meant drains are responsible for some of these emboli as suggested by Dr. Barnett?

Suprapubic tubes long enough to rest in the prostatic cavity and perineal drains reaching the same distance are well placed to disturb the clots in the surrounding veins as the patient moves about. Is there any need of tubes after either operation? There will be no back pressure of urine with a good sized opening in the bladder and we would welcome an early closure of the incision we make, provided the patient does not suffer thereby.

The deaths under the heading of Cardiac and General Debility are many of them uncertain. Some with autopsy would have been called uremic and some embolic. Some apparently represent the general giving out of the machine after the accident of prostatectomy and some a myocarditis.

It is not yet possible to say what the mortality of the operation should be hecause operators

have such varied methods in their selection of cases.

A surgeon who believes that every old man suffering from prostatic obstruction is entitled to a chance of operative cure will have a higher mortality than the surgeon who refuses the desperate cases.

One skilful operator says privately that by selecting his cases he has done over ninety prostatectomies with one fatal result, and in contrast there is a mortality in some excellent hospitals of $20 \%$ or more. It is certain that the mortality rate is lower than it was ten years ago and a large credit is due Drs. Rowntree and Geraughty's study of color elimination in its relation to renal competency, for the improvement.

Before this work appeared many of us knew the wisdom of preliminary drainage but now we have a measure of the time necessary for this. Until some better method is made applicable, no prostatectomy should be done without testing the capacity of the kidneys for color elimination, using some chemical at least as reliable as phenolsulphonephthalein. By this intelligent delay many cases can be transferred from the desperate to the reasonably safe class of risks and those truly inoperable can obtain some measure of relief from their misery.

A STUIDY OF 'THE EFFICIENCY OF IIIXEI) TOXINS (COLEY) IN INOPERABLE SARCONA. A CRITICAL ANALY. SIS OF 134 MICROSCOPICALLY PROVEN CASES.

By 'Tork Wagner Hakmer. M.I., boston,

Assistant in Anatomy, Ilarvard Medical School; Junior Assistant Surgeon, Children's Hospital; A8sistant in Suryery, Massachusetts Genoral. Hospital.

(C'oncluded from page 116.)

Case Rhports.

BoNs, (Not Giant Cell).

Case 86. (Case No. 41. and Annals of Surgery, 1913, vol. lviii.) Periosteal round cell sarcoma of femur with multiple metastases. A. G., 18, male. An extensive growth involving lower twothirds of shaft of femur proved on microscopical examination to be small round cell sarcoma. Amputation at hip joint refused. $\Lambda$ fter prolonged $\mathrm{x}$ ray treatment, extensive motastases doveloped in pectoral and ilio-lumbar regions, involving ilium. Pectoral mass partially excised.

Pathological report. Round cell sarcoma. Toxin treatment instituted. In four weeks ilio-lumbar growth became necrotic and was drained. No trace of recurrence $101 / 2$ years later. Subsequently there developed epithelioma at site of x-ray dermatitis on chest and malignant tumors (epithelioma and sarcoma) at sight of $x$-ray dermatitis on thigh. The latter grew rapidly. Amputation was refused. Lung 